\title{
Recovery of Silicon Dioxide from Waste Foundry Sand and Alkaline Activation of Desilicated Foundry Sand
}

\author{
Tebogo Mashifana ${ }^{1}$ (D) Thandiwe Sithole $^{1}$
}

Received: 14 May 2020 / Accepted: 8 October 2020 / Published online: 10 November 2020

(c) The Author(s) 2020

\begin{abstract}
This study was conducted to recover silica (desilication) as a valuable metalloid from waste foundry sand (WFS) by a leaching process and to find application for desilicated foundry sand (DFS). The leaching time applied was $5 \mathrm{~h} ; 3 \mathrm{M}$ of potassium hydroxide (KOH) was used as a leaching reagent. The agitation speed of $200 \mathrm{rpm}$ and the liquid/solid ratio of 25 were found to be the best conditions for optimum leaching results. A geopolymer from DFS was developed by using $\mathrm{NaOH}$ as an alkaline activator. The results obtained showed that the optimum conditions for the synthesis of a geopolymer were $15 \mathrm{M} \mathrm{NaOH}$, $150 \mu \mathrm{m}$ DFS particle size, and a curing temperature of $80{ }^{\circ} \mathrm{C}$ for $72 \mathrm{~h}$. The geopolymer strength development was due to the formation of Phillipsite and Kalsilite as new hydration products. At the optimum alkaline solution concentration, the highest unconfined compressive strength (UCS) of 4.8 MPa was achieved. The developed geopolymer met the minimum strength requirements for load bearing material. This study provides an innovative and novel solution for the beneficiation of spent foundry sand and the recovery of a valuable metalloid, resulting to zero waste generation.
\end{abstract}

The contributing editor for this article was João António Labrincha Batista.

Tebogo Mashifana

tmashifana@uj.ac.za

1 Department of Chemical Engineering, University

of Johannesburg, P.O. Box 17011, Doornfontein 2088,

South Africa 


\section{Graphical Abstract}

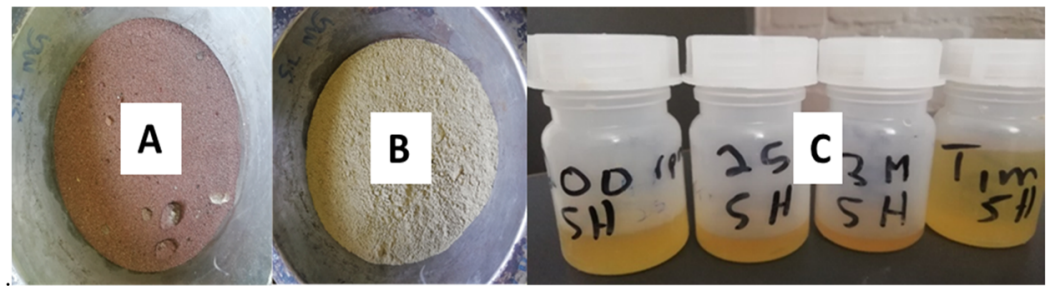

Fig. 1 (a) Foundry sand, (b) desilicated foundry sand, (c) silica pregnant solution
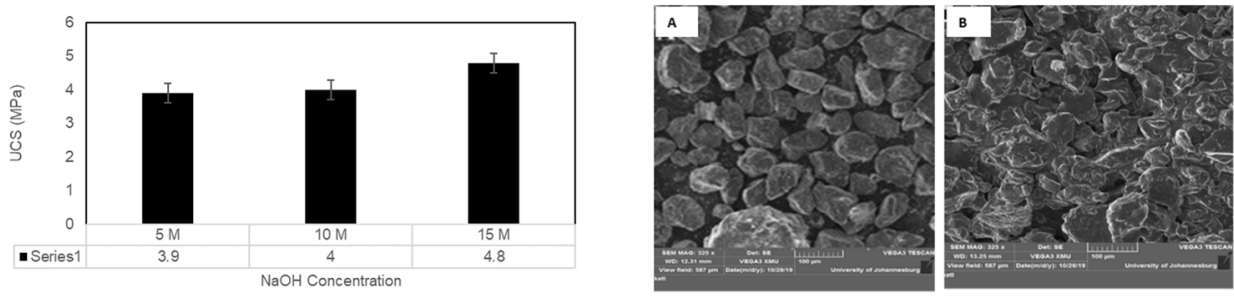

Fig 2 Effect of $\mathrm{NaOH}$ concentration on the UCS

Fig. 3 SEM of (a) WFS (b) specimen cured at $80{ }^{\circ} \mathrm{C}$ for $72 \mathrm{~h}$.

Table 1. Elemental composition of WFS AND DFS

\begin{tabular}{llllllllllllll}
\hline & $\mathrm{Na}_{2} \mathrm{O}$ & $\mathrm{MgO}$ & $\mathrm{Al}_{2} \mathrm{O}_{3}$ & $\mathrm{SiO}_{2}$ & $\mathrm{P}_{2} \mathrm{O}_{5}$ & $\mathrm{SO}_{3}$ & $\mathrm{Cl}$ & $\mathrm{K}_{2} \mathrm{O}$ & $\mathrm{CaO}$ & $\mathrm{TiO}_{2}$ & $\mathrm{Cr}_{2} \mathrm{O}_{3}$ & $\mathrm{Fe}_{2} \mathrm{O}_{3}$ & $\mathrm{ZrO}_{2}$ \\
\hline WFS & 0.22 & 0.06 & 2.09 & 95.18 & 0.02 & 0.74 & 0.04 & 0.40 & 0.06 & 0.29 & 0.07 & 0.68 & 0.07 \\
DFS & 1.32 & 0.06 & 1.88 & 36.56 & 0.04 & 0.53 & 0.06 & 57.41 & 0.14 & 0.41 & 0.21 & 1.29 & 0.06 \\
\hline
\end{tabular}

Keywords Desilication · Geopolymer · Resource recovery $\cdot$ Spent foundry sand $\cdot$ Waste beneficiation

\section{Introduction}

The high amount of waste foundry sand (WFS) produced in South Africa and the high disposal costs have necessitated the development of a solution to deal with the waste generated. WFS has been the focus of extensive research in recent years. South Africa has been reported to have more than 200 casting facilities [1]. The foundry industry generates approximately 350,000 tons of silica sand [2]. Due to the land issue the country is facing, the environmental pollution as a result of the wastes, and the high penalties the foundry industry pay for the disposal of spent foundry sand, the dumping of wastes on the landfill has become a problem for most of these foundry industries. When compared to other countries, the country is facing an over prize for waste disposal, whereby approximately R 63.91 is applicable for disposal in United Kingdom and R505.43 in South Africa [2].

About 3,000 foundries in the United States of America utilize 100 million tons of sand, which result in generating 6-10 million metric tons of foundry waste that is discarded to the landfills annually [3, 4]. Between 2012 and 2013, 9.3 million metric tons of WFS was reported [5].

From a sustainability perspective, the reuse of WFS to better the infrastructure development is favorable in all viewpoints: (1) ecologically: natural resources are preserved and space in landfills is spared, (2) economically: WFS is less expensive since it is found from other industries and there will be no need for the industries to pay large amounts of money to dump the waste, (3) socially: it has a minor effect on humans and the environment [6], and (4) it provides a solution to environmental pollution, whereby the sand pollutes the air during windy weather conditions and contaminates ground water when it is raining. The foundry sand used in this study is predominated with constituents such as silica and aluminum, which present an opportunity for the recovery of silicon metalloid, changing a perspective to view the sand as a resource instead of waste.

Metal recovery/removal from numerous waste materials is widely studied and investigated. Xiao et al. [7] investigated the recovery of silica from vanadium-bearing steel slag using a leaching process and sodium hydroxide solution as a leaching reagent [7]. The results obtained showed that most of the silica was successfully removed from the slag and a residue produced contained low content of $\mathrm{SiO}_{2}$ content and a high $\mathrm{V}_{2} \mathrm{O}_{5}$. Several researchers have shown that biomass and silica fumes [8] can be used to supplement cementitious materials in building and construction materials because of the silica content in most of the materials. 
These processes have been reported to reduce greenhouse gas emissions and energy consumption. The biomass used is from waste such as sugar cane bagasse ash [9-12] and rice husk ash (RHA) [13, 14]. Akbar et al. [14] developed sugarcane bagasse ash (SBA) geopolymer, which incorporated propylene fibers. The prevalent element of sugar cane bagasse ash was $\mathrm{SiO}_{2}$ with a relative proportion of $66.7 \%$. $12 \mathrm{M}$ sodium hydroxide $(\mathrm{NaOH})$ and $2.5 \mathrm{M}$ sodium silicate $\left(\mathrm{Na}_{2} \mathrm{SiO}_{3}\right)$ were combined and used as alkaline activators. The geopolymers were cured for 7, 14, and 28 days. The highest unconfined compressive strength (UCS) was about $18 \mathrm{MPa}, 22.5 \mathrm{MPa}$, and $25 \mathrm{MPa}$ for the curing ages investigated, respectively. The study showed that well-structured geopolymer composites were provided by the reaction of amorphous silicates in SBA with alkaline activators at elevated temperature [14]. Nguyen et al. [15] used rice husk ash and coal bottom with sodium silicate solutions to develop geopolymers. Low energy consumption and reduced carbon dioxide emission were reported as the advantages for the geopolymerization process. The developed geopolymer specimens were cured at room temperature for 28 days and rice husk showed to have silica content of over $80 \mathrm{wt} \%$. Geopolymers with optimum UCS of $32.8 \mathrm{MPa}$ were developed from RHA and waste glass [16]. RHA proved to be the main source of silica with a content of $83.05 \mathrm{wt} \%$.

Geopolymerization is a chemical process between alkali metal silicate solutions and solid aluminosilicate oxides at mild temperatures and alkaline conditions. The process yields $\mathrm{Si}-\mathrm{O}-\mathrm{Si}$ and $\mathrm{Si}-\mathrm{O}-\mathrm{Al}$ amorphous to semi-crystalline structures [17]. Silica and aluminum play a significant role in geopolymerization process, with silica making the structure and bonding of the geopolymer [18]. Under alkaline conditions of $\mathrm{pH}>11$, an alkali activator interacts with metals-metalloids to generate three-dimensional polymers ( $\mathrm{Si}-\mathrm{O}-\mathrm{Si}, \mathrm{Al}-\mathrm{O}-\mathrm{Si}$ ) [18-23].

Desilicated foundry sand (DFS) is a by-product of WFS leaching. Studies show that the silica extraction on WFS can be conducted using potassium hydroxide as a leaching reagent. DFS contains minimal amount of silica, which can be a solution to the dry shrinkage, difficulties in construction, and temperature cracks during construction [24].

Geopolymers are alumina-silicate materials, which are synthesized in alkali solutions. The alumina-silicate compound causes the material to have a good fire-resistant performance and influences the thermal performance of a geopolymer. A geopolymer has a three-dimensional structure, which consists of $\mathrm{AlO}_{4}$ and $\mathrm{SiO}_{4}$ tetrahedra, which share all the oxygen atoms. Geopolymers are made by the alkaline activation of material and curing at medium temperatures; this promotes the process of polymerizations to produce pastes, which settles and hardens to produce solid materials [25]. Jamieson et al. [26] studied the development of Bayer geopolymers for aggregates formation [26]. In the study,
Bayer solution and fly ash were used to produce geopolymers with compressive strength more than $30 \mathrm{MPa}$ [26].

Although research is being conducted for the beneficiation of WFS, there are limited studies reported on the use of DSF for building and construction applications. This therefore presents an opportunity for research in this area as it will allow for the use recovery of metalloid and use of WFS, which will result in reducing the waste disposal to the landfills. This study presents a novel and a holistic zero waste solution for the recovery of silica as a valuable metalloid from WFS and the development of geopolymers from DFS. Resource recovery and waste beneficiation were successfully achieved in this study.

\section{Materials and Methods}

\section{Materials}

The foundry sand was collected from a local South African foundry. Desilicated foundry sand (DFS) was generated from the leaching process. Potassium hydroxide $(\mathrm{KOH})$ was used as a leaching reagent and sodium hydroxide $(\mathrm{NaOH})$ as the alkaline activator.

\section{Method: Leaching Process}

The leaching process was carried out in a thermostatic shaker by varying and studying the following parameters: (1) leaching time; (2) liquid-to-solid ratio (L/S) from 20 to $30 \%$; (3) $\mathrm{KOH}$ concentration from 1 to $4 \mathrm{M}$; (4) particle size distribution; (5) agitation speed from 100 to $200 \mathrm{rpm}$. For all the tests conducted under different leaching conditions, samples were taken at $1 \mathrm{~h}$ interval, filtered, and characterized. The effect of leaching time was studied by allowing leaching process under the following conditions: $5 \mathrm{~h}$, liquid-to-solid ratio (L/S) of $25 \%, 2 \mathrm{M} \mathrm{NaOH}$ solution, agitation speed of $150 \mathrm{rpm}$, leaching temperature of $90{ }^{\circ} \mathrm{C}$ and foundry sand particle size as received. Using the optimum conditions obtained in step 1, to study the effect of S/L, the following conditions were applied: $2 \mathrm{M} \mathrm{KOH}, 5 \mathrm{~h}$ leaching time, temperature of $90{ }^{\circ} \mathrm{C}$, foundry sand as received. The L/S ratio was varied from 20 to $30 \%$. The next study conducted was to investigate the effect of $\mathrm{KOH}$ concentration on silica recovery, and the following conditions were applied, which were optimum in steps 1 and 2: $5 \mathrm{~h}$ leaching time, L/S ratio of 25 , agitation speed of $150 \mathrm{rpm}$, leaching temperature of $90{ }^{\circ} \mathrm{C}$, and foundry sand particle size as received. The concentration of $\mathrm{KOH}$ solution was varied from $1 \mathrm{M}, 2 \mathrm{M}, 3 \mathrm{M}$, and $4 \mathrm{M}$. To study the effect of particle size on the leaching of silica, the foundry sand was sieved into different sizes $75,150,300 \mu \mathrm{m}$, and as received. The following optimum leaching conditions were applied: $5 \mathrm{~h}$ leaching time, $\mathrm{L} / \mathrm{S}$ 
ratio of 25 , agitation speed of $150 \mathrm{rpm}$, leaching temperature of $90{ }^{\circ} \mathrm{C}$, and $3 \mathrm{M} \mathrm{KOH}$ concentration. The effect of agitation speed on the recovery of silica was studied by varying the speed from $100 \mathrm{rpm}, 150 \mathrm{rpm}$, and $200 \mathrm{rpm}$ under the optimum leaching conditions obtained in step 1-4.

\section{Desilication of Foundry Sand}

Silica extraction was conducted by using a thermostatic shaker. The analysis of silica leached was achieved by analyzing the leachate using an Atomic Absorption Spectrometer (Thermo scientific ICE 3000 Series). The yield was obtained by incorporating the volume change as presented in Eq. 1 [27].

$$
\% \mathrm{SiO}_{2}=\frac{\left(V_{0}-\sum_{i=1}^{i=1} V_{i}\right) C_{\mathrm{SiO}_{2}}+\left(\sum_{i=1}^{i=1} V_{i} C_{\mathrm{SiO}_{2 \mathrm{i}}}\right)}{m\left(\frac{C_{\mathrm{SiO}_{2}}}{100}\right)} .
$$

Here $V_{0}$ is the initial volume (mL) of the solution, $V_{i}$ is the volume $(\mathrm{mL})$ of the ith sample, $C_{\mathrm{SiO} 2}$ is the content of silica in the Camden Power Station FA (wt\%), $C_{\mathrm{SiO} 2 \mathrm{i}}$ is the concentration of silica in sample $\mathrm{i}(\mathrm{mg} / \mathrm{L})$, and $\mathrm{m}$ is the initial mass of FA $(\mathrm{g})$ added into the reflux reactor [24, 27].

\section{Method: Geopolymerization Process}

The leaching conditions that yielded the optimum recovery of silica were then used to leach foundry sand to generate DFS for the development of geopolymers. It is reported that sodium is the better reagent for the preparation of geopolymers, as compared to potassium [28]. This is due to $\mathrm{Na}^{+}$ cation being better in promoting alumino-silicates than $\mathrm{K}^{+}$ cations [28]. Geopolymers were developed by mixing DFS with $\mathrm{NaOH}$ solution as the alkaline activation reagent. $300 \mathrm{~g}$ of DFS was mixed with a $60 \mathrm{ml} \mathrm{NaOH}$ solution. The optimum concentration of $\mathrm{NaOH}$ was investigated by varying the solution from $5 \mathrm{M}, 10 \mathrm{M}$, and $15 \mathrm{M}$. After the development of a workable paste using different concentrations, the different paste was cast into a $50 \times 50 \times 50 \mathrm{~mm}^{3}$ molds. The cast specimens were allowed to set and then removed from the molds. The effect of curing temperature on the UCS of the geopolymers was investigated by curing the specimens at different temperatures of $40{ }^{\circ} \mathrm{C}, 80^{\circ} \mathrm{C}$, and $100{ }^{\circ} \mathrm{C}$ for $24 \mathrm{~h}, 48 \mathrm{~h}$, and $72 \mathrm{~h}$. The effect of PSD of DFS on the UCS was also studied by varying the particle size between $75 \mu \mathrm{m}, 150 \mu \mathrm{m}$, and $300 \mu \mathrm{m}$. The specimens were produced in triplicate to ensure consistency in the results. After curing, the specimens were measured for unconfined compressive strength (UCS) in compliance with ASTM C 109 [29], using a Universal Testing Machine (UTM) with a capacity of $300 \mathrm{kN}$ on the specimens. The porosity of the developed geopolymer was determined. Porosity is defined as the ratio of volume of voids to the total volume and open porosity is the fraction of volume that is occupied by the fluid in the interconnected porous network [30]. The porosity of the composites was determined by following ASTM C373-14 a [31]. The dry weight was determined, and the composites soaked in water for $24 \mathrm{~h}$. After the soaking period, the wet geopolymer was weighed. Open porosity was then calculated using Eq. 2 [24].

$f=\frac{\left(W_{s}-W_{d}\right)}{V \alpha}$,

where $f$ is open porosity, $W_{\mathrm{s}}$ is the mass of the soaked composite, $W_{\mathrm{d}}$ the mass of the dry composite, $V$ the volume of the composite, and $\alpha$ is the density of water [24].

\section{Characterization}

The raw foundry and DFS were characterized for elemental composition by X-ray fluorescence (XRF; model Magix Pro Phillips). $10 \mathrm{~g}$ of the dried sample and $3 \mathrm{~g}$ of Sasol wax were weighed. The Sasol wax and dried material was mixed using a pastel and mortar. The mixed sample was stored in the aluminum cup and pressed to 25 tons. The pressure was released after $2 \mathrm{~min}$. The chemical analysis was carried out on the $13 \mathrm{~g}$ pressed sample using wavelength dispersive. The mineralogy of DFS and geopolymer that yielded the highest UCS was studied by X-ray diffraction (XRD, model Rigaku Ultima IV). A representative sample containing $10 \mathrm{~g}$ material was milled using a mortar and pestle. A sample holder was used to mount a sample, mounted in a manner to minimize preferred orientation for XRD analysis. Scanning Electron Microscope (SEM; model Jeol JSM 5600) was used to study morphology of the geopolymers at different curing periods. The materials were carbon coated and mounted onto SEM particle morphology determination. The analysis of variance (ANOVA) was applied to investigate the significance of difference in the investigated variables. A statistical significance confidence level limit of $95 \%$ was used for the tests [32]. $F$ value and critical $F$ value were utilized to evaluate the significance in varying the variables investigated. $F$ value can be defined as a ratio of two variances, measuring how far the data are scattered from the mean or the dispersion [32]. It is calculated as shown in Eq. 3. This is conducted from computer generated data comparing the value of variables investigated [32].

$F_{\text {value }}=\frac{\text { varience of the group means(Mean Square Between })}{\text { mean of the within group variances(Mean squared Error })}$. 


\section{Results and Discussion}

\section{Elemental Composition of Foundry Sand}

Table 1 shows the elemental composition of WFS.

The chemical composition of WFS is influenced and depends on the type of binders used for casting, metal molded, and combustible used [33]. The WFS used in this study was predominated with $\mathrm{SiO}_{2}$ and $\mathrm{Al}_{2} \mathrm{O}_{3}$. The sand is rich in silica with a relative proportion of $95.18 \mathrm{wt} \%$. Minor constituents of $\mathrm{Cl}, \mathrm{CaO}, \mathrm{MgO}$, and $\mathrm{ZrO}_{2}$ were also detected. In the study by [33], $\mathrm{SiO}_{2}$ and $\mathrm{Al}_{2} \mathrm{O}_{3}$ were reported to have the highest relative proportion of $87.91 \mathrm{wt} \%$ and $4.71 \mathrm{wt} \%$, respectively. Basar and Aksoy [34] investigated the effect of WFS as partial replacement of sand on the ready-mixed concrete. The XRF results of the WFS also showed $\mathrm{SiO}_{2}$ and $\mathrm{Al}_{2} \mathrm{O}_{3}$ as predominant constituents with relative proportion of $97.38 \mathrm{wt} \%$ and $1.89 \mathrm{wt} \%$, respectively.

To measure the $\mathrm{pH}$ of WFS, $50 \mathrm{~g}$ of WFS was added into $100 \mathrm{~mL}$ of deionized water under continuous stirring and the $\mathrm{pH}$ was measured after $30 \mathrm{~min}$. According to Johnson [35], the $\mathrm{pH}$ of WFS is dependent on the type of metal cast, the binder used, and it normally ranges between 4 and 8 . In the study conducted by [36], on the evaluation of physical and chemical properties of South Africa waste found sand, 39 WFS from steel, iron, and aluminum were studied and the $\mathrm{pH}$ value ranging from 6.7 to 10.2 was reported [36]. The $\mathrm{pH}$ was found to be 9.10, indicating that the sand is basic and within the range of reported WFS $\mathrm{pH}$.

\section{Leaching of WFS}

\section{Effect of Leaching Time}

Figure 1 shows silica yield with variation in time.

The leaching of silica increased by $44 \mathrm{~g} \mathrm{SiO}_{2} / \mathrm{kg}$ sand from the first hour to the second hour. From the third to fourth hour, silica yield increased from 74 and $81 \mathrm{~g} \mathrm{SiO}_{2} /$ $\mathrm{kg}$, respectively. At $5 \mathrm{~h}$ leaching, silica yield was $151 \mathrm{~g} \mathrm{SiO}_{2} /$ $\mathrm{kg}$. A $70 \%$ difference in yield was achieved between the fourth and fifth hour of leaching. $5 \mathrm{~h}$ was therefore taken as the leaching time with maximum silica yield. $5 \mathrm{~h}$ leaching period was based on the study conducted by Falayi et al. [24], whereby $6 \mathrm{~h}$ was the optimum leaching period for the desilication of fly ash. Xu et al. [37] investigated the desilication and recycling of alkali silicate solution with red mud and the time employed for leaching was $3 \mathrm{~h}$.

Table 1 Elemental composition of WFS

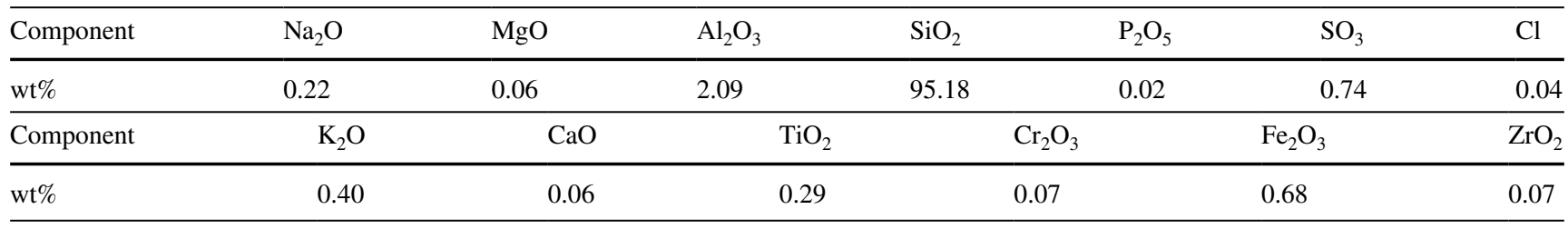

Fig. 1 Variation in silica yield with time. N.B: $2 \mathrm{M} \mathrm{KOH,}$ agitation speed of $150 \mathrm{rpm}$, temperature $90{ }^{\circ} \mathrm{C}, \mathrm{L} / \mathrm{S}$ ratio of 20

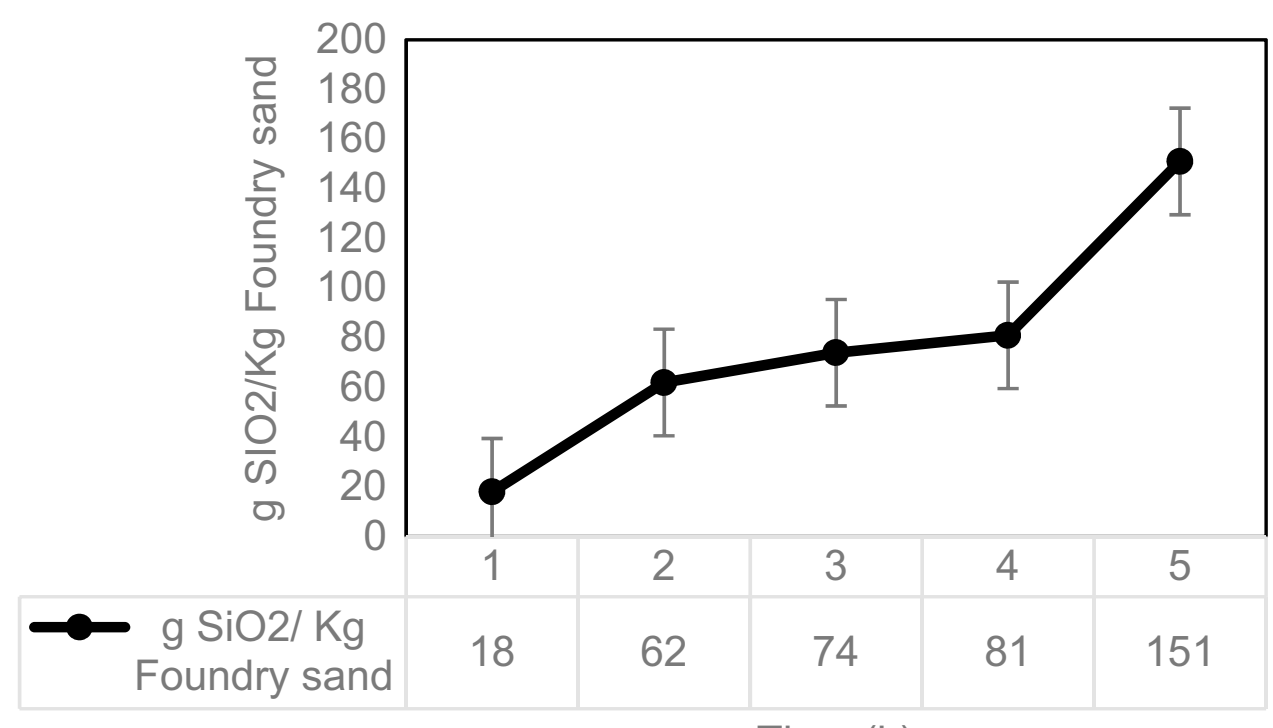

Time (h) 


\section{Effect of L/S Ratio}

Figure 2 shows the silica yield with variation in L/S ratio.

Figure 2 shows that the increase of L/S ratio from 20 to 30 resulted in the higher silica yield. This is due to an increase in solid loading, which results in reduction of efficient mass transfer [38]. The maximum yield of $337 \mathrm{~g}$ $\mathrm{SiO}_{2} / \mathrm{kg}$ of WFS was achieved for $\mathrm{L} / \mathrm{S}$ of 25 . The $\mathrm{L} / \mathrm{S}$ of 30 resulted in a decrease by $122 \mathrm{~g} \mathrm{SiO}_{2} / \mathrm{kg}$ from $\mathrm{L} / \mathrm{S}$ ratio of 25 . This is due to the decrease in the amount of solid per amount of reagent in the reaction mixture. Table 2 shows the ANOVA computation of $\mathrm{SiO}_{2}$ removal with variation in liquid-solid ratio. The $\mathrm{L} / \mathrm{S}$ of 25 was chosen as the optimum leaching L/S load.

A critical value of 5.3177 was obtained, a value less than the $F$ value of 17.8398 . This shows a significant difference in the recovery of $\mathrm{SiO}_{2}$ with different $\mathrm{L} / \mathrm{S}$ ratios of 25 and 30 . The $\mathrm{L} / \mathrm{S}$ of 25 was taken as the optimum and then utilized to conduct further tests.

\section{Effect of $\mathrm{KOH}$ Concentration}

Figure 3 shows silica yield with variation of $\mathrm{KOH}$ concentration. There was an increase in the yield of silica as the $\mathrm{KOH}$ concentration was increased. This is due to the increase in the $\mathrm{OH}^{-}$anion available for leaching. Silica yield at $2 \mathrm{~h}$ and $3 \mathrm{~h}$ for $3 \mathrm{M}$ and $4 \mathrm{M}$ was almost similar. However, at $4 \mathrm{~h}$ and $5 \mathrm{~h}$ leaching period, a slight decrease on the yield of silica from the $3 \mathrm{M}$ to the $4 \mathrm{M}$ was observed. A high concentration of $\mathrm{KOH}$ has been reported to result in the codissolution of alumina, which reacts with silica and precipitate cancrinite or sodalite [39]; this explains the sudden decrease in the yield of silica in $4 \mathrm{M}$ medium. Table 3 shows the ANOVA computation of $\mathrm{SiO}_{2}$ removal with variation of $\mathrm{KOH}$ concentration. $3 \mathrm{M}$ had the maximum yield of silica and was chosen as the leaching concentration.

A critical value of 5.3177 was obtained, a value greater than the $\mathrm{F}$ value of 0.1033 . This shows that there was no significant difference in the recovery of $\mathrm{SiO}_{2}$ when $3 \mathrm{M}$ and $4 \mathrm{M} \mathrm{KOH}$ was used as a leaching reagent. The concentration of $3 \mathrm{M}$ was then utilized to conduct further tests.
Fig. 2 Silica yield with variation in liquid-solid ratio. N.B: Time 5 h, $2 \mathrm{M} \mathrm{KOH}$, agitation speed of $150 \mathrm{rpm}$, temperature $90{ }^{\circ} \mathrm{C}$
Table 2 ANOVA computation of $\mathrm{SiO}_{2}$ removal with variation of liquid-solid ratio

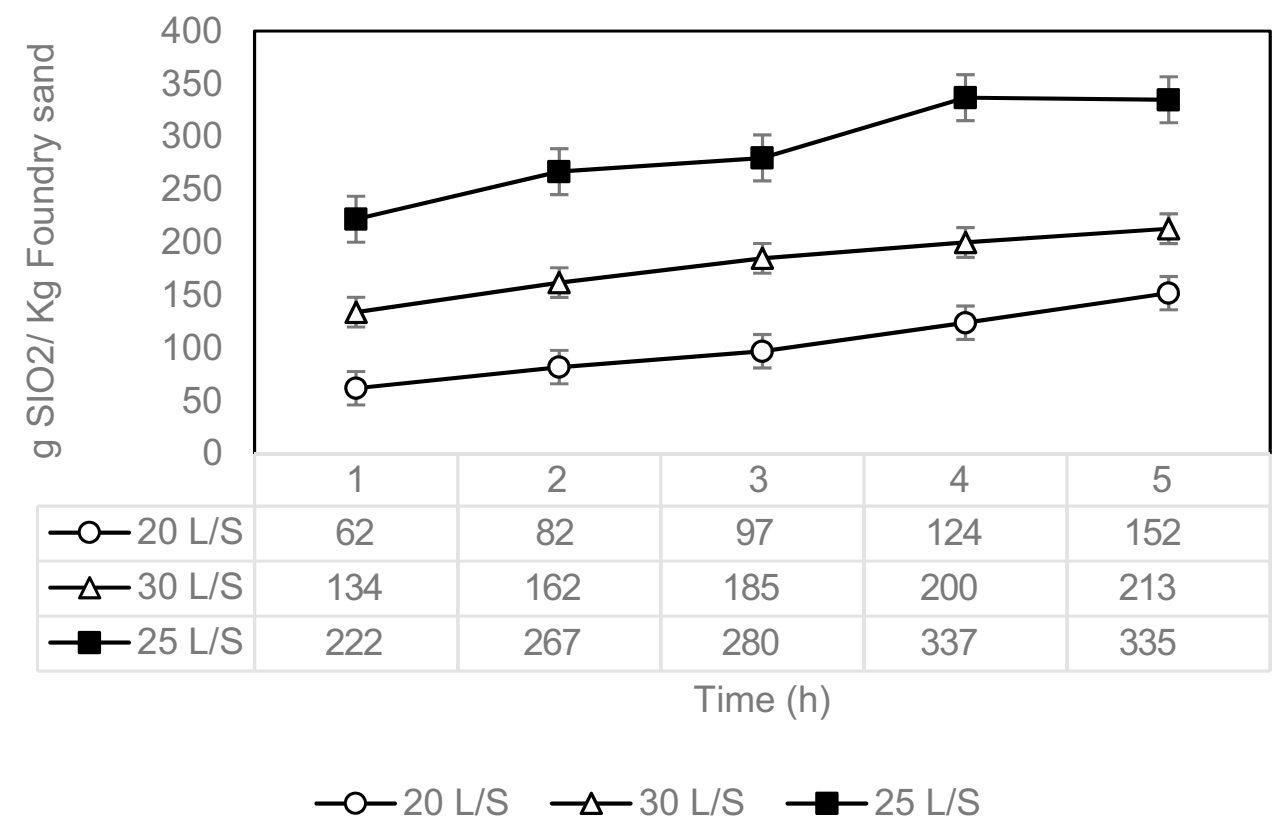

\begin{tabular}{llllllll}
\hline Source & SS & $\%$ SS & Df & VAR & $F$ & $P$ value & $F$ critical \\
\hline Between groups (SSB) & $29,920.90$ & $69.04 \%$ & 1 & $29,920.90$ & 17.8398 & 0.0029 & 5.3177 \\
Within groups (SSW) & $13,417.60$ & $30.96 \%$ & 8 & 1677.20 & & & \\
Total (SST) & $43,338.50$ & & 9 & & & & \\
\hline
\end{tabular}

$S S$ sum of squares, $D f$ degree of freedom, VAR variance, SST total sum of squares, SSB some of squares within groups, $F$ ANOVA coefficient, $P$ value probability of making a type I error that is calculated from data, $F$ critical statistic that is determined by an ANOVA test

It determines the significance of the groups of variables 
Fig. 3 Silica yield with variation in concentration. Time $5 \mathrm{~h}$, agitation speed of $150 \mathrm{rpm}$, temperature $90{ }^{\circ} \mathrm{C}, \mathrm{L} / \mathrm{S}$ ratio of 25 , foundry sand particle size as received

Table 3 ANOVA computation of $\mathrm{SiO}_{2}$ removal with variation of concentration

Fig. 4 Silica yield with variation in PSD. N.B: Time $5 \mathrm{~h}$, $3 \mathrm{M} \mathrm{KOH}$, temperature $90{ }^{\circ} \mathrm{C}$, $\mathrm{L} / \mathrm{S}$ ratio of 25 , agitation speed of $150 \mathrm{rpm}$

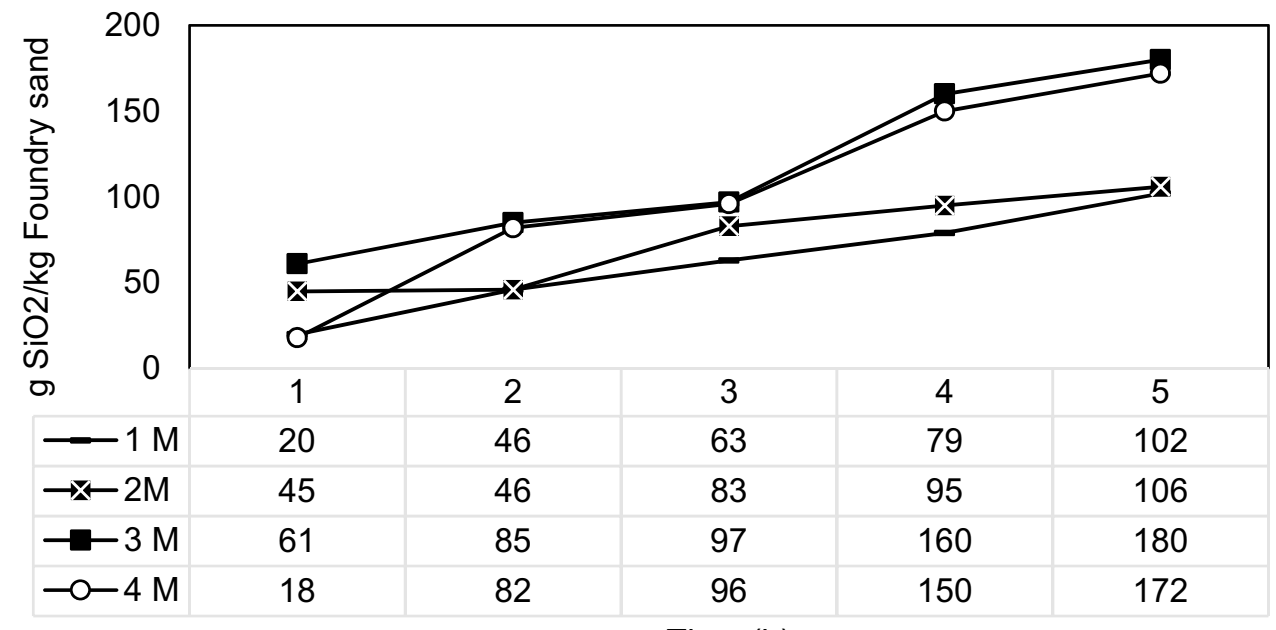

Time (h)

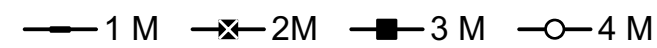

\begin{tabular}{lrrrrrrr}
\hline Source & \multicolumn{1}{c}{ SS } & \multicolumn{1}{c}{$\%$ SS } & Df & \multicolumn{1}{l}{ VAR } & $F$ & $P$ value & $F$ critical \\
\hline Between groups (SSB) & 313.60 & $1.27 \%$ & 1 & 313.60 & 0.1033 & 0.7562 & 5.3177 \\
Within groups (SSW) & $24,288.40$ & $98.73 \%$ & 8 & 3036.05 & & & \\
Total (SST) & $24,602.00$ & & 9 & & & & \\
\hline
\end{tabular}

$S S$ sum of squares, $D f$ degree of freedom, VAR variance, $S S T$ total sum of squares, $S S B$ some of squares within groups

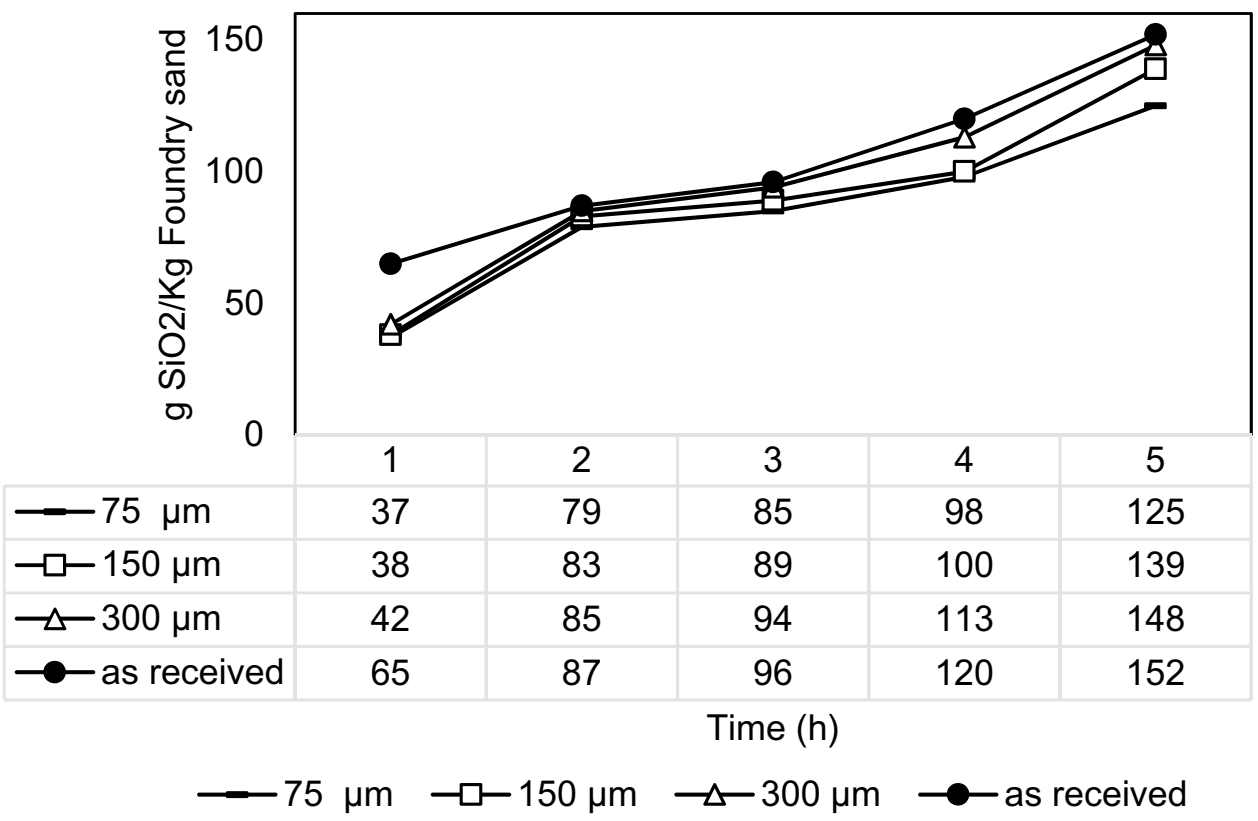




\section{Effect of Particle Size Distribution (PSD)}

Figure 4 shows silica yield with variation in PSD.

There was a very slight difference in silica yield with the variation of particle size. At $5 \mathrm{~h}$, the yield of silica for $75 \mu \mathrm{m}$ particles was $130 \mathrm{~g} \mathrm{SiO}_{2} / \mathrm{kg}$ WFS, $139 \mathrm{~g} \mathrm{SiO}_{2} / \mathrm{kg}$ FS for $150 \mu \mathrm{m}, 148 \mathrm{~g} \mathrm{SiO}_{2} / \mathrm{kg}$ WFS for $300 \mu \mathrm{m}$, and $152 \mathrm{~g}$ $\mathrm{SiO}_{2} / \mathrm{kg}$ WFS particle size as received. This is because the particle size of WFS entailed over $85 \%$ of particle size below 400 microns. Over $50 \%$ of WFS particle size was less than $75 \mu \mathrm{m}$. Therefore, the particle size did not have a major effect on the $\mathrm{SiO}_{2}$ yield. The WFS particle size as received was chosen as the optimum.

\section{Effect of Agitation Speed}

Figure 5 shows silica yield with variation in agitation speed.

As the agitation speed was increased from 100 to $150 \mathrm{rpm}$, there was an increase in silica yield. At $5 \mathrm{~h}$, the yield of silica was $69 \mathrm{~g} \mathrm{SiO}_{2} / \mathrm{kg}$ WFS for $100 \mathrm{rpm}$ and $96 \mathrm{~g}$ $\mathrm{SiO}_{2} / \mathrm{kg}$ WFS for $150 \mathrm{rpm}$. This is due to the increase in contact between the $\mathrm{KOH}$ and the foundry sand. The silica yield increased further from 150 to $200 \mathrm{rpm}$ by $14 \mathrm{~g} \mathrm{SiO}_{2} /$ $\mathrm{kg}$. The $200 \mathrm{rpm}$ was taken as the leaching agitation speed.
Elemental Composition of Foundry Before and After Silica

\section{Recovery}

The comparison of elemental composition for WFS and DSF is presented in Table 4.

The DFS was characterized by a low silica content due to leaching of silica. This also shows that silica was successfully leached from the foundry sand, as the relative proportion of silica decreased significantly from 95 to 37 $\mathrm{wt} \%$. There was also a decrease in the relative proportion of alumina in DFS from 2.0924 to $1.8826 \mathrm{wt} \%$. The $\mathrm{pH}$ of DFS was found to be 11.15 and higher than that of WFS, as DFS has more basic oxides than WFS; thus, the significant increase in the relative proportion of $\mathrm{K}_{2} \mathrm{O}$, which increased from 0.4 to $57.41 \mathrm{wt} \%$, contributed to the higher alkalinity.

Figure 6 shows the WFS before and after leaching and the silica solution after it was extracted from WFS.

From Fig. 6, it is evident that leaching WFS with $\mathrm{KOH}$ completely transformed the color of the sand. The sand changed from a dark brown color to cream like color, as silica was removed from the sand. The extracted silica can be used as a precursor for production of zeolites and xerogels [24].
Fig. 5 Silica yield with variation of agitation speed. Time 5 h, $3 \mathrm{M} \mathrm{KOH}$, temperature $90{ }^{\circ} \mathrm{C}$, Foundry sand as received, L/S ratio of 25

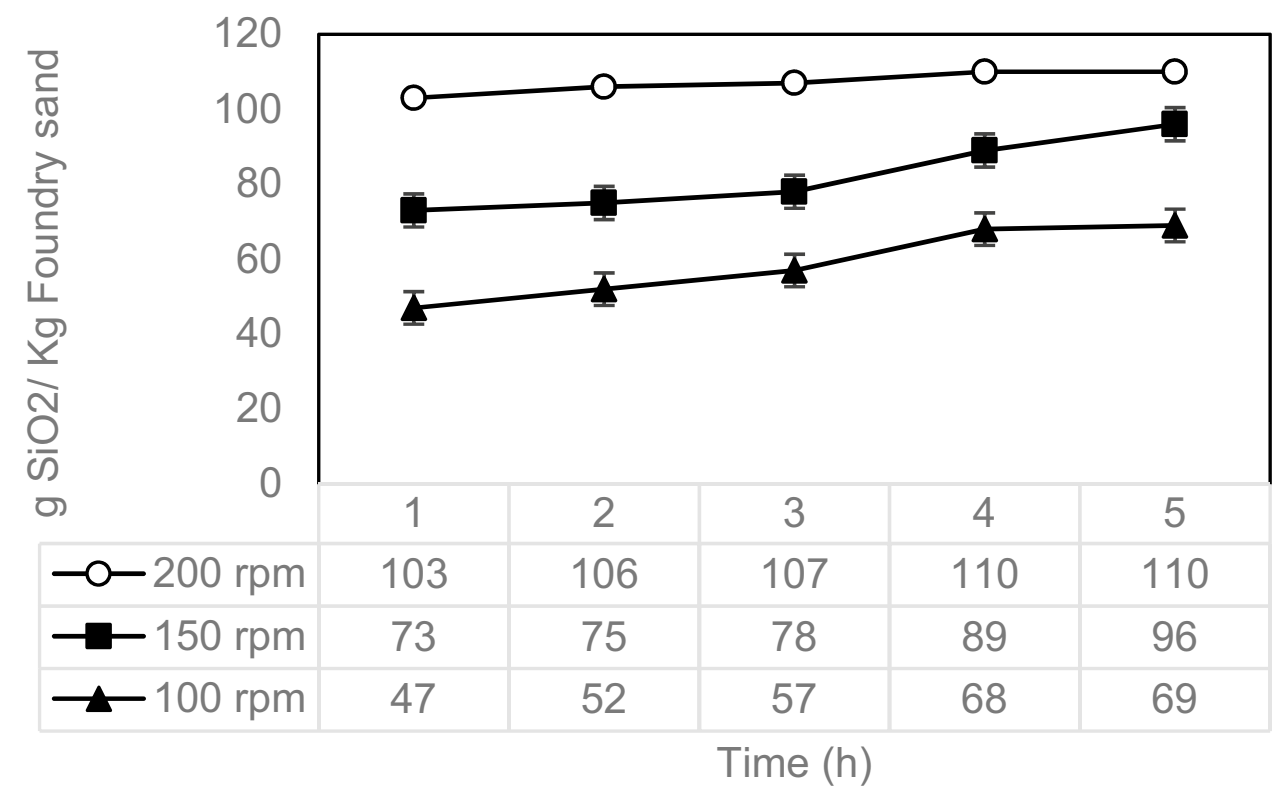

-0-200 rpm $\rightarrow-150 \mathrm{rpm} \rightarrow-100 \mathrm{rpm}$

Table 4 Elemental composition of WFS AND DFS

\begin{tabular}{lllllllllllllll}
\hline & $\mathrm{Na}_{2} \mathrm{O}$ & $\mathrm{MgO}$ & $\mathrm{Al}_{2} \mathrm{O}_{3}$ & $\mathrm{SiO}_{2}$ & $\mathrm{P}_{2} \mathrm{O}_{5}$ & $\mathrm{SO}_{3}$ & $\mathrm{Cl}$ & $\mathrm{K}_{2} \mathrm{O}$ & $\mathrm{CaO}$ & $\mathrm{TiO}_{2}$ & $\mathrm{Cr}_{2} \mathrm{O}_{3}$ & $\mathrm{Fe}_{2} \mathrm{O}_{3}$ & $\mathrm{ZrO}_{2}$ \\
\hline WFS & 0.22 & 0.06 & 2.09 & 95.18 & 0.02 & 0.74 & 0.04 & 0.40 & 0.06 & 0.29 & 0.07 & 0.68 & 0.07 \\
DFS & 1.32 & 0.06 & 1.88 & 36.56 & 0.04 & 0.53 & 0.06 & 57.41 & 0.14 & 0.41 & 0.21 & 1.29 & 0.06 \\
\hline
\end{tabular}




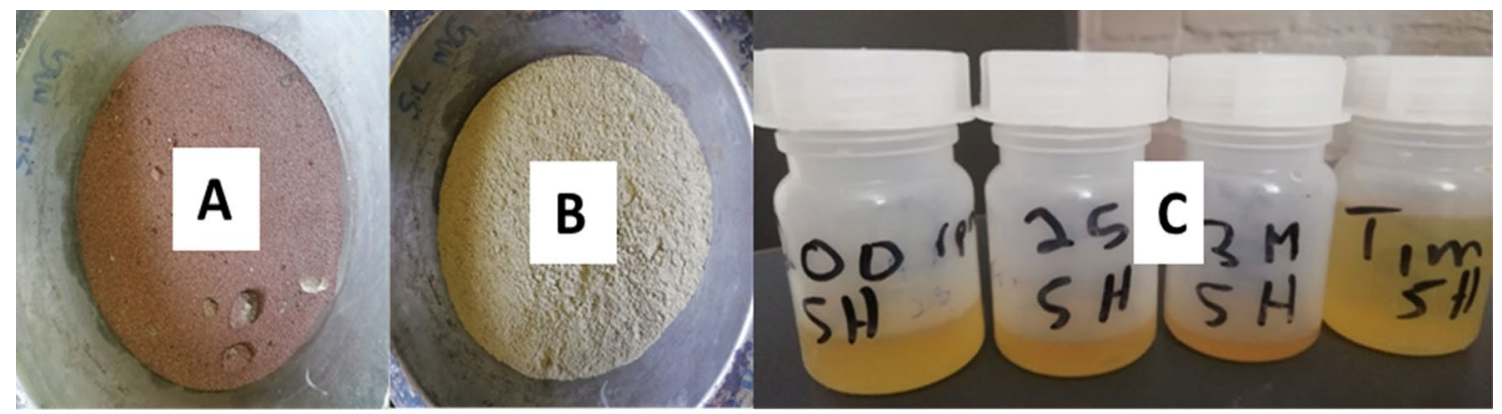

Fig. 6 a Foundry sand, b desilicated foundry sand, $\mathbf{c}$ silica pregnant solution

\section{Geopolymerization of DFS}

This section presents the development of the geopolymers from DFS. The geopolymers were developed by studying the effect of $\mathrm{NaOH}$ concentration, particle size, temperature, and curing regime. The geopolymers were tested for the unconfined compressive strength (UCS).

\section{Effect of $\mathrm{NaOH}$ Concentration on the UCS}

Figure 7 shows the UCS results obtained for the geopolymerization of DFS with variation in $\mathrm{NaOH}$ concentration. The specimens were cured at $80{ }^{\circ} \mathrm{C}$ for $72 \mathrm{~h}$. In the comparison of the best alkaline activator for the synthesis of geopolymers, it was reported that geopolymers developed with $\mathrm{NaOH}$ attained strength higher than that of $\mathrm{KOH}$ solution [40]. $\mathrm{NaOH}$ was therefore selected as an activator due to the $\mathrm{Na}^{+}$cations, which are more active than $\mathrm{K}^{+}$and tend to favor better dissolution process of raw material [41, 42]

As $\mathrm{NaOH}$ concentration was increased from 5 to $15 \mathrm{M}$, there was an increase in UCS. Higher concentrations of alkali enhance the geopolymerization, whereas the type of alkali also affects the process. The use of sodium hydroxide as an activator regulates hydration. The $\mathrm{Na}^{+}$ions have a greater charge, which makes the sodium hydroxide to dissolve $\mathrm{Si}$ and $\mathrm{Al}$ fast. The use of $\mathrm{NaOH}$ produces an extra silicate in the system and allows the geopolymerization process to accelerate, which leads to the development of UCS [43]. Geopolymers are said to gain strength when alkaline solutions and aluminum silica-rich source materials react [44]. The polymer chain of inorganic aluminum silicate polymer is structured around tetrahedral coordinated $\mathrm{Si}^{4+}$ and $\mathrm{Al}^{3+}$ [44]. The XRD results presented in Fig. 11 also show high peak associated to $\mathrm{SiO}_{2}$, showing that silica might have not reacted in the process. It is also possible that the silica that was not recovered and remained in DFS was in crystal phases, which is inert, unreacted, and did not take part in the fabrication of a geopolymer, which contributed to the lower strength attained $[45,46]$. In the strength development in either $\mathrm{NaOH} / \mathrm{KOH}$-based geopolymer, $\mathrm{Na}_{2} \mathrm{O}$ is the major alkali oxide required [47]. However, in this study, $\mathrm{Na}_{2} \mathrm{O}$ constituent was $1.32 \mathrm{wt} \%$ for DFS, which also explains the lower strengths attained.

In the study to develop a geopolymer from waste foundry sand for building material, Doğan-Sağlamtimur [6] reported 2.5 $\mathrm{MPa}$ as the minimum compressive strength achieved, which was acceptable for building wall materials. It can therefore be concluded that the geopolymers developed in
Fig. 7 Effect of $\mathrm{NaOH}$ concentration on the UCS

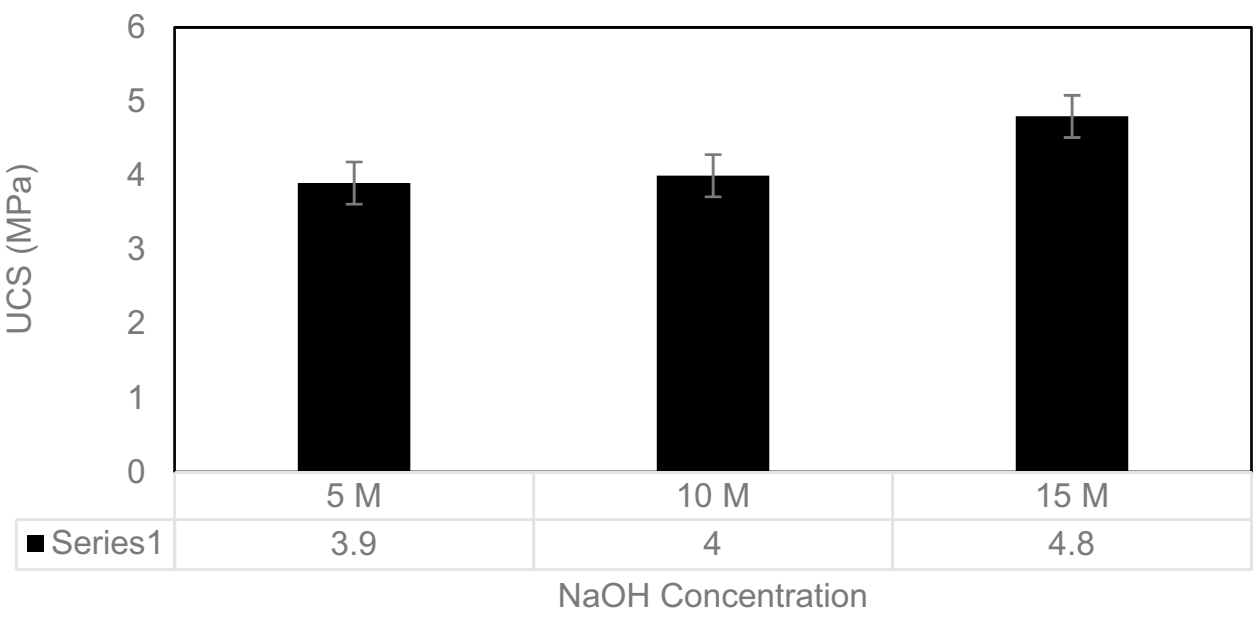


this study with the UCS between 3.9 MPa to 4.8 MPa can be used for different applications. Taking into consideration that the geopolymer did not entail the required constituents to contribute to the strength development, which is mainly the aluminate silica constituent, the developed DFS geopolymers can be categorized as innovative sustainable building and construction material.

\section{Effect of Curing Temperature and Regime}

The activator that yielded the highest UCS was then used to study the effect of temperature and regime. Figure 8 shows the variation in UCS with curing regimes. There was an increase in UCS with increasing time up to $48 \mathrm{~h}$ within the same curing region. Thereafter, there was a slight increase in UCS at $72 \mathrm{~h}$. An increase in UCS with temperature increase from 40 to $80{ }^{\circ} \mathrm{C}$ was also observed. The increase in UCS is attributed to the high rate of the geopolymerization process, which increased the rate of hardening of the DFS paste. An increase in curing temperature from 80 to $100{ }^{\circ} \mathrm{C}$ resulted in a decrease in UCS. The condensation-polymerization process has been reported to be complete at $80{ }^{\circ} \mathrm{C}$, hence the decrease in compressive strength beyond $80{ }^{\circ} \mathrm{C}$. The condensation of geopolymer is endothermic and heat plays an important role in the reaction and curing of the DFS paste. There was a rapid loss of moisture at $100{ }^{\circ} \mathrm{C}$. This led to the reduction in time for equilibrium, reorganization, and hardening, which would result in a stronger geopolymer [48]. Although the temperature of $80^{\circ} \mathrm{C}$ yielded the highest UCS, the strength is low as compared to the strength of geopolymers reported in the literature. This is attributed to the low $\mathrm{SiO}_{2}$ and $\mathrm{Al}_{2} \mathrm{O}_{3}$ ratio, which was recovered and plays a significant role in the development of a geopolymer.
Fig. 8 UCS with variation in curing conditions

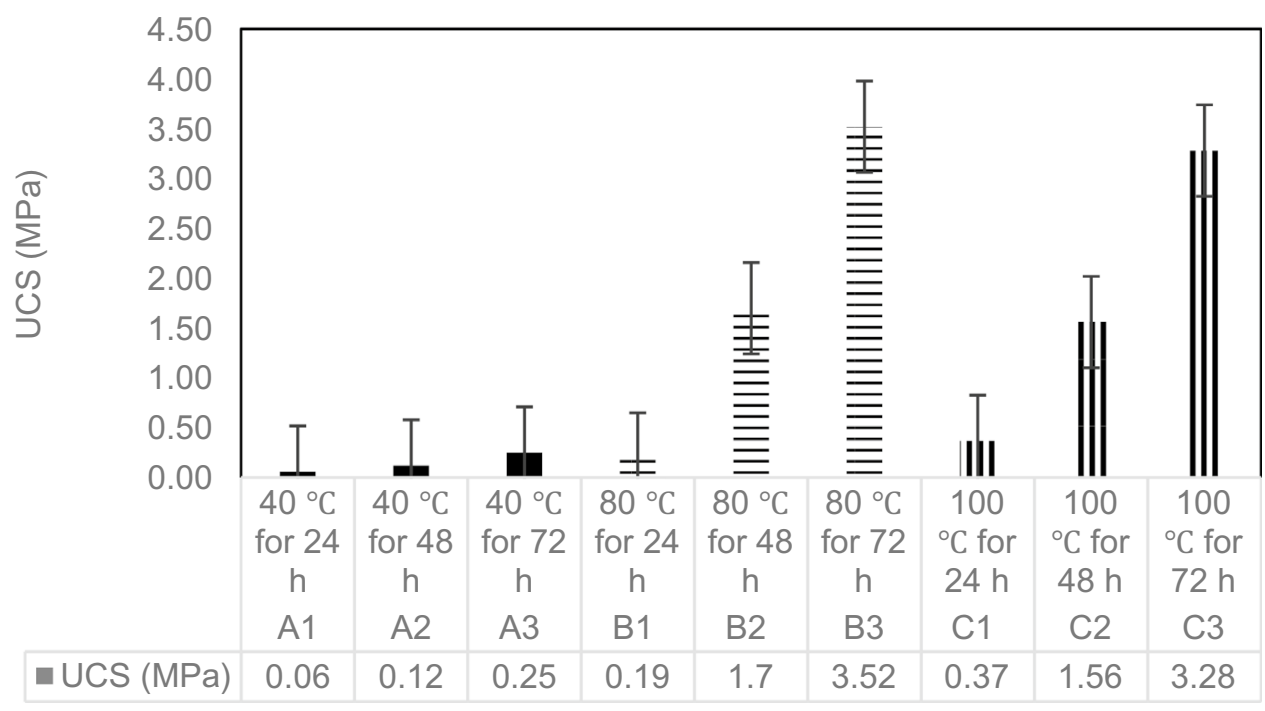

Fig. 9 Effect of PSD on UCS

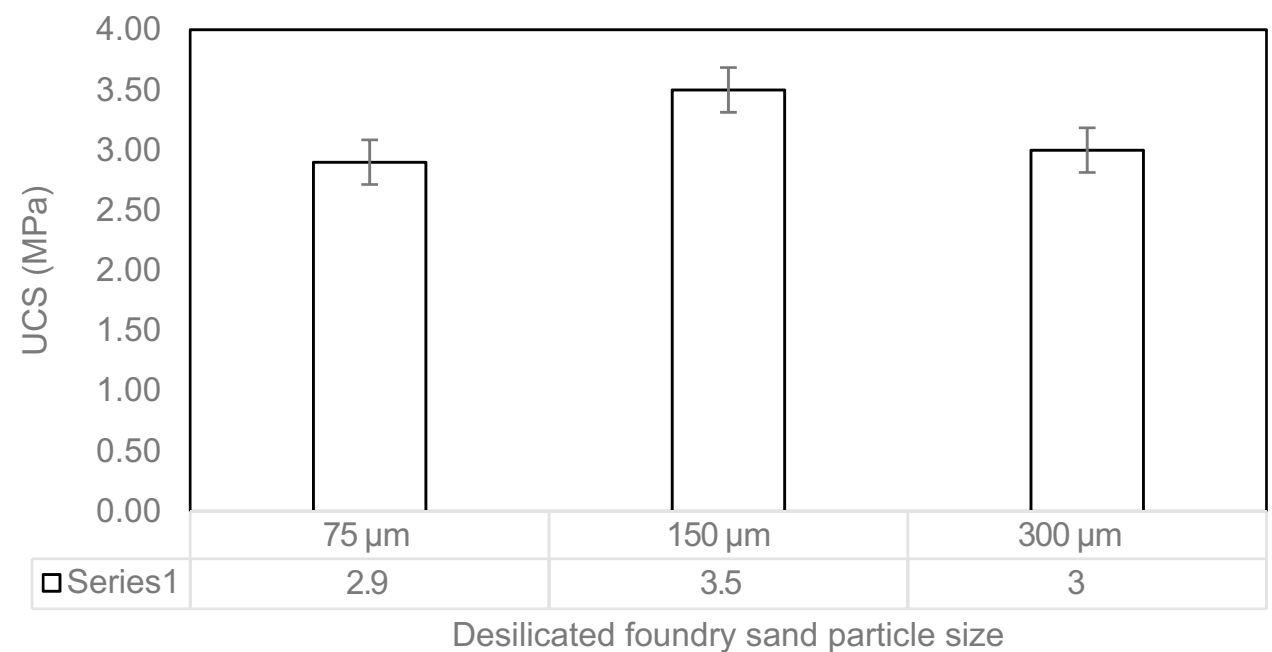




\section{Effect of PSD on the UCS}

To study the effect of PSD on the UCS, the alkaline activator and curing temperature and regime that resulted in the highest UCS were used (Fig. 9).

The $150 \mu \mathrm{m}$ was found to be the optimum particle size, which yielded the highest UCS from the geopolymers developed. The particle size reacted faster and resulted in higher unconfined compressive strength. The $75 \mu \mathrm{m}$ resulted in an increase in particle number, which would impede mass transfer [24]. The particles larger than $150 \mu \mathrm{m}$ had less surface area to allow for effective dissolution of aluminosilicate species. Kim and Lee [49] investigated the effect of PSD on the compressive strength for geopolymers developed from different fly ash materials, namely, fine ground bottom ash $(50.5 \mu \mathrm{m})$, medium-sized bottom ash $(102.4 \mu \mathrm{m})$, and coarse ground bottom ash $(196.7 \mu \mathrm{m})$ [49]. Fine ground bottom ash, the material with the smaller particle size, yielded the highest strength; this was because of PSD. The authors found that with larger particles size, the reaction between alumina and silica required for dissolution is reduced [49]. However, in this study, the smallest DFS particle size investigated resulted in the lowest strength of $2.9 \mathrm{MPa}$.

\section{Microstructure of Developed Geopolymers}

Figure 10 shows the microstructure of WFS and DFS geopolymers cured at $80{ }^{\circ} \mathrm{C}$ for $72 \mathrm{~h}$. WFS is made up of angular, sub-angular, and round particle shapes [36]. The mechanism of geopolymerization is seen from time-based SEM analysis. The geopolymer shows a heterogeneous morphology on the surface. The geopolymer is more compact as compared to WFS particles, indicating the particles bonded together. The surface of geopolymer is porous; this is due to
Table 5 Porosity of geopolymer after $24 \mathrm{~h}$ soaking

\begin{tabular}{ll}
\hline Parameter & DFS geopolymer \\
\hline Mass of cured sample $(\mathrm{g})$ & 198.10 \\
Mass of cured sample after 24 h soak $(\mathrm{g})$ & 202.35 \\
UCS before soak $(\mathrm{MPa})$ & 3.52 \\
UCS after soak $(\mathrm{MPa})$ & 3.13 \\
$\%$ water absorption & 2 \\
$\%$ reduction in UCS & 11 \\
Open porosity & 0.17 \\
\hline
\end{tabular}

the addition of sodium hydroxide, where the matrix became loose, with low space filling properties through the DSF activation formation of a gel [50]; this was supported by the open porosity of the geopolymer after $24 \mathrm{~h}$ in water, which is 0.17 , as shown in Table 5 . After $24 \mathrm{~h}$ of water soaking, the UCS of the geopolymer reduced by $11 \%$. The geopolymer showed only $2 \%$ water absorption.

\section{Mineralogy of DFS and Geopolymer}

Figure 11 shows the XRD diffractograms for DFS and the Geopolymer cured at $80{ }^{\circ} \mathrm{C}$ for $72 \mathrm{~h}$. The XRD shows the patterns of the geopolymer and DFS. The XRD reveals that there are crystalline phases present in the geopolymer, as the sharp intensity peaks are seen. The quartz are the remnant peaks in the geopolymer due to the unreacted DFS particles. In the study to synthesize sodium silicate from WFS, the micrograph of the WFS showed a rough surface after acid leaching Aleem et al. [51]. Boussaa et al. [52] reported a thinner surface for solid WFS sample after leaching. This explains the lower UCS obtained for DFS geopolymers as
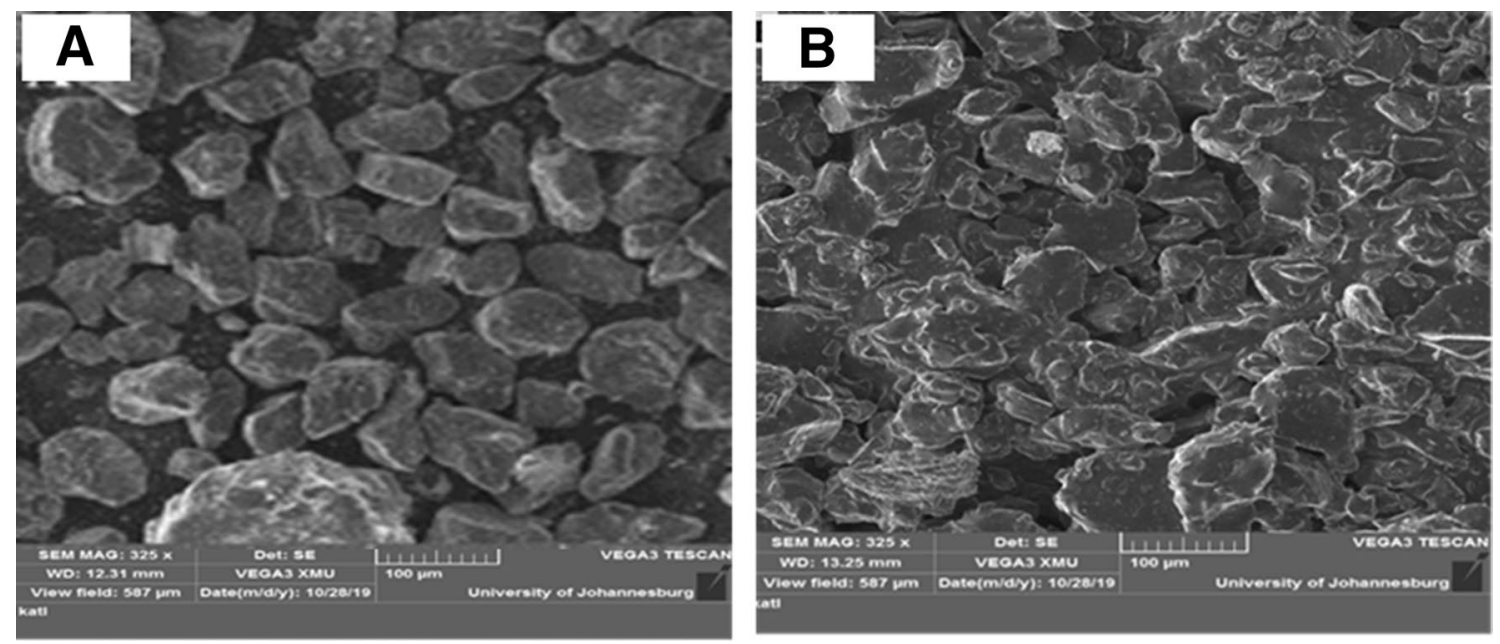

Fig. 10 SEM of a WFS, b specimen cured at $80^{\circ} \mathrm{C}$ for $72 \mathrm{~h}$ 


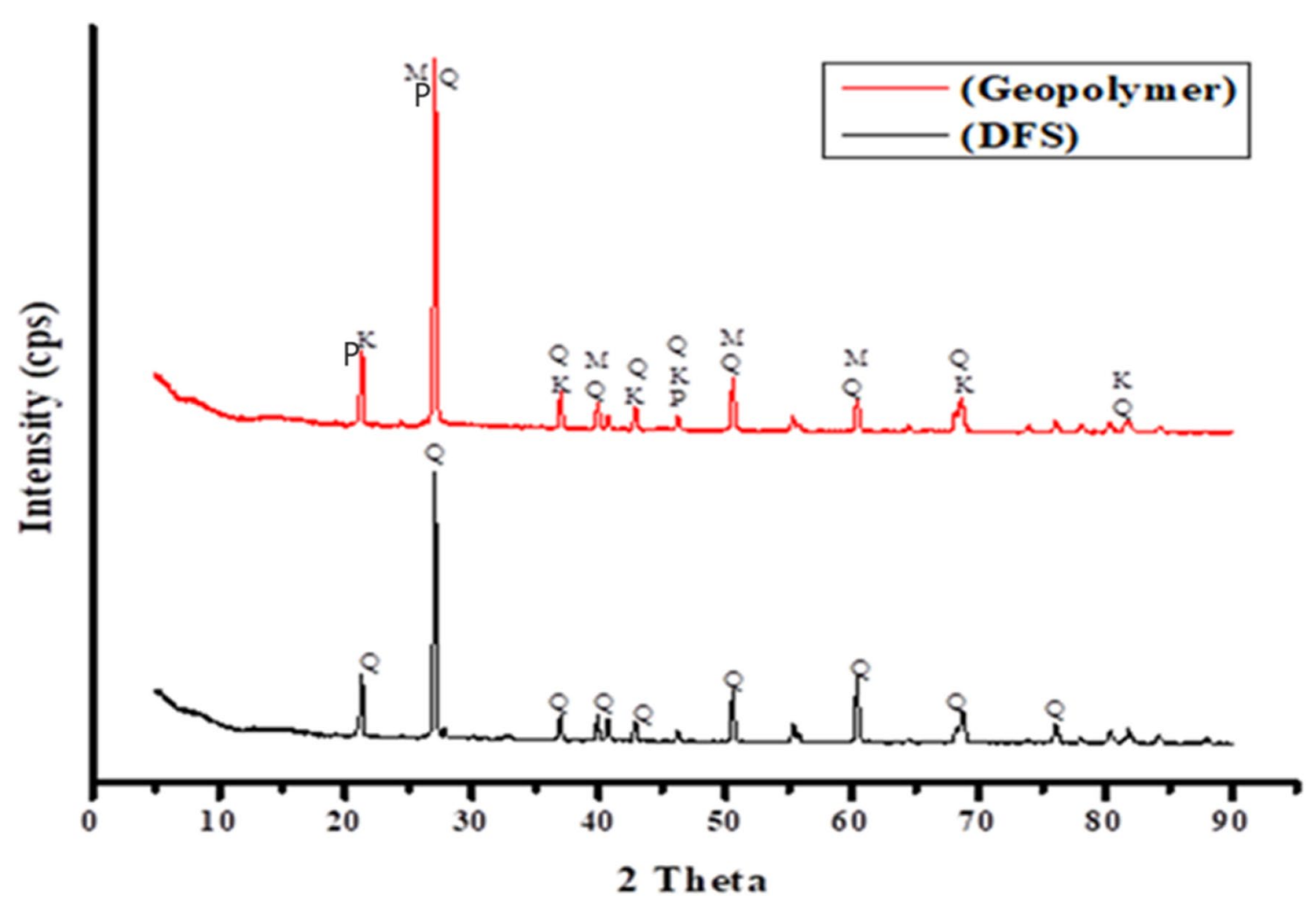

Fig. 11 XRD of DFS and geopolymer ( $P$ phillipsite, $M$ mullite, $K$ kalsilite)

compared to the high UCS of geopolymers developed from WFS [6, 44, 53, 54].

The XRD analysis of WFS was predominated with quartz $\left(\mathrm{SiO}_{2}\right)$; this agrees with the elemental analysis results, which showed a relative proportion of $95.8 \mathrm{wt} \%$ for $\mathrm{SiO}_{2}$. The mineralogy results reported by Iloh et al. [20] also showed high peaks associated with silica in the WFS studied. Geopolymerization resulted in an increase in the intensity of Zeolite phillipsite K. Geopolymerization also resulted in the formation of kalsilite, which is seen in the XRD diffractogram at around $37^{\circ}$ and resulted in the formation of mullite, which is seen in the XRD diffractogram at around $21^{\circ}$. Kalsilite and the Phillipsite are responsible for the strength development as their presence on zeolitic material increases the strength of the geopolymer. The peak for quartz was high in the developed geopolymer, indicating that the geopolymerization process was not complete and not all the silica in DFS reacted [55]. This, therefore, supports the lower strength that was obtained.

\section{Image of Geopolymer Developed}

The geopolymer developed at optimum conditions, with the highest UCS presented in Fig. 12. The product was intact and the highest strength of $3.52 \mathrm{MPa}$ is applicable for load

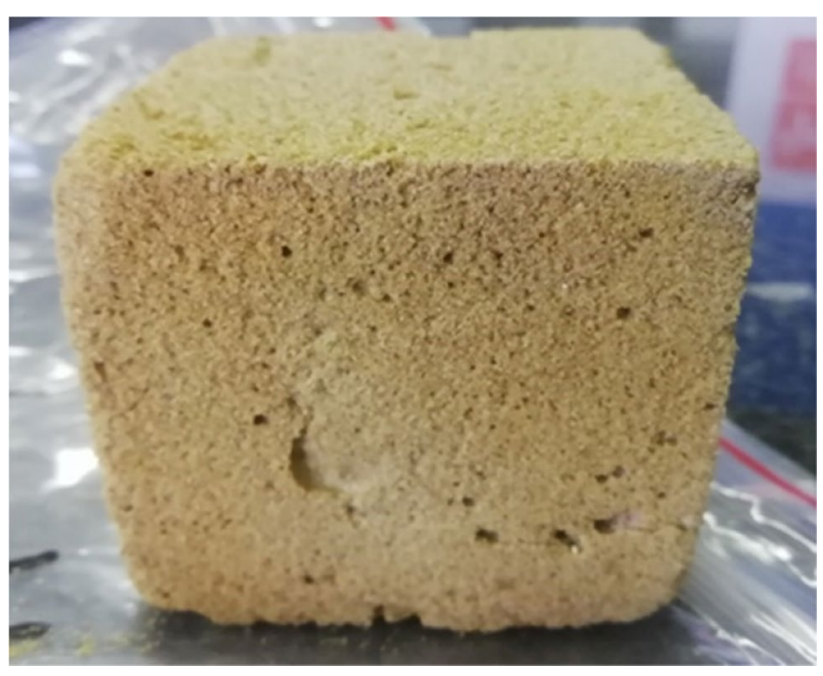

Fig. 12 Geopolymer cured at $80{ }^{\circ} \mathrm{C}$

bearing applications. In terms of UCS and durability, the developed geopolymer has equivalent strength values as C1-C4 materials, which is applicable for subbase [56]. The product also meets the requirements of South African Roads specification. According to SANS 1215, it is also applicable for masonry brick production [57]. 


\section{Environmental Impact of WFS and DFS Geopolymer}

The US Environmental Protection Authority (US EPA, 2015) conducted a risk assessment study to examine the environmental effects of WFS to the environment [58]. The results obtained showed WFS may produce some environmental benefits and with application that does not harm human health. Studies by Dungan et al. [59] showed that under the conditions they have investigated, WFS has low metal leaching potential and when the sand was subjected to Toxicity characteristic leaching procedure (TCLP), it passed the toxicity characteristics. In the evaluation of silica-based WFS generated from iron, aluminum, and steel foundries, it was reported that the sand does not pose any hazardous concerns when used in manufactured soils [60]. Deng [61] evaluated contaminants in waste foundry sand and its leachate. He tested 594 WFS samples from 123 foundries in US. The results obtained showed that WFS is non-hazardous, except for the sand generated from copper-based foundries [615]. With this information, it is therefore concluded that WFS used in this study has minimal potential to affect the environment negatively.

\section{Conclusions}

This study investigated the desilication of WFS and geopolymerization of DFS. The results obtained show that $\mathrm{KOH}$ can successfully recover silica from WFS and $\mathrm{NaOH}$ is an effective activator for the development of geopolymers from desilicated foundry sand. The best leaching parameters were $3 \mathrm{M} \mathrm{KOH}, \mathrm{L} / \mathrm{S}$ ratio of 25 , particle size as received, agitation speed of $200 \mathrm{rpm}$, and leaching time of $5 \mathrm{~h}$. Foundry sand can be used as a source of silica. The desilicated foundry sand can be used as a precursor for geopolymer reactions. The particle size, concentration, and quantity of $\mathrm{NaOH}$ and curing regime have a direct effect on the geopolymer brick strength. $\mathrm{NaOH}$ can be used to alkali activate DFS for the development of load bearing geopolymers. $\mathrm{SiO}_{2}$ and $\mathrm{Al}_{2} \mathrm{O}_{3}$ ratio plays a significant role in the development of a geopolymer. To improve the strength of the geopolymers developed in this study, alkali sodium silicate can be used, to make up for the silica recovered from the WFS. Curing temperature played a significant role in the strength of DFS geopolymer. The XRD analysis showed a possible unreacted $\mathrm{SiO}_{2}$, and it has been proven that longer curing periods results in strength development. Longer curing periods up to 28 days, at ambient temperature, should be investigated and is highly recommended for DFS-based geopolymer. The study showed that it was possible to use WFS as a source of silica and alkali activate the residual solids from the leaching process to produce geopolymers. The study was a success as the objectives were successfully achieved. The study provides an opportunity for the beneficiation of WFS and recovery of silica as a valuable metalloid. The recovered silica metalloid can be recovered in pure metal form by using reductive crystallization and be utilized in different applications. The geopolymers attained the UCS of. 4.8 MPa and thus show a great potential for the geopolymers developed to be used for load bearing application in building or construction.

Acknowledgements The authors would like to thank the University of Johannesburg and National Research Foundation of South Africa for the financial support, Grant Unique Number:112237.

\section{Compliance with Ethical Standards}

Conflict of interest On behalf of all authors, the corresponding author states that there is no conflict of interest.

Open Access This article is licensed under a Creative Commons Attribution 4.0 International License, which permits use, sharing, adaptation, distribution and reproduction in any medium or format, as long as you give appropriate credit to the original author(s) and the source, provide a link to the Creative Commons licence, and indicate if changes were made. The images or other third party material in this article are included in the article's Creative Commons licence, unless indicated otherwise in a credit line to the material. If material is not included in the article's Creative Commons licence and your intended use is not permitted by statutory regulation or exceeds the permitted use, you will need to obtain permission directly from the copyright holder. To view a copy of this licence, visit http://creativecommons.org/licenses/by/4.0/.

\section{References}

1. Nyembwe KJ, Makhatha ME, Mageza K (2017) WFS mineralogical characterisation: the impact of cast alloy, casting temperature and molding additive on the nature WFS. Eng J 21(7):1-14

2. Madzivhandila T (2018) Waste sand management in South African foundries (Doctoral dissertation, University of Johannesburg)

3. Winkler ES, Bol'shakov AA (2000) Characterization of foundry sand waste. Chelsea Centre for Recycling and Economic Development, University of Massachusetts, Amherst

4. Siddique R, De Schutter G, Noumowe A (2009) Effect of usedfoundry sand on the mechanical properties of concrete. Constr Build Mater 23(2):976-980

5. Bhardwaj B, Kumar P (2017) WFS in concrete: a review. Constr Build Mater 156:661-674

6. Doğan-Sağlamtimur N (2018) WFS usage for building material production: a first geopolymer record in material reuse. Adv Civ Eng. https://doi.org/10.1155/2018/1927135

7. Xiao Q, Chen Y, Gao Y, Xu H, Zhang Y (2010) Leaching of silica from vanadium-bearing steel slag in sodium hydroxide solution. Hydrometallurgy 104(2):216-221

8. Brew DRM, MacKenzie KJD (2007) Geopolymer synthesis using silica fume and sodium aluminate. J Mater Sci 42(11):3990-3993

9. Cordeiro GC, Kurtis KE (2017) Effect of mechanical processing on sugar cane bagasse ash pozzolanicity. Cem Concr Res 97:41-49

10. Deepika S, Anand G, Bahurudeen A, Santhanam M (2017) Construction products with sugarcane bagasse ash binder. J Mater Civ Eng 29(10):04017189 
11. Lyra GP, dos Santos V, De Santis BC, Rivaben RR, Fischer C, Pallone EMDJA, Rossignolo JA (2019) Reuse of sugarcane bagasse ash to produce a lightweight aggregate using microwave oven sintering. Constr Build Mater 222:222-228

12. Sales A, Lima SA (2010) Use of Brazilian sugarcane bagasse ash in concrete as sand replacement. Waste Manage 30(6):1114-1122

13. Ambedkar B, Alex J, Dhanalakshmi J (2017) Enhancement of mechanical properties and durability of the cement concrete by RHA as cement replacement: experiments and modeling. Constr Build Mater 148:167-175

14. Akbar A, Farooq F, Shafique M, Aslam F, Alyousef R, Alabduljabbar H (2020) Sugarcane bagasse ash-based engineered geopolymer mortar incorporating propylene fibers. J Build Eng 33:101492

15. Nguyen HT, Pham TK, Promentilla MA (2017) Development of geopolymer-based materials from coal bottom ash and rice husk ash with sodium silicate solutions. In: Tran-Nguyen HH, Wong H, Ragueneau F, Ha-Minh C (eds) Congrès International de Géotechnique-Ouvrages-Structures. Springer, Singapore, pp 402-410

16. Tchakouté HK, Rüscher $\mathrm{CH}$, Kong $\mathrm{S}$, Kamseu E, Leonelli $\mathrm{C}$ (2016) Geopolymer binders from metakaolin using sodium waterglass from waste glass and rice husk ash as alternative activators: a comparative study. Constr Build Mater 114:276-289

17. Davidovits J, Orlinski J (1999) 99 Geopolymer International Conference Proceedings. Geopolymer Institute, Saint-Quentin

18. Do QM, Hoang MD, Nguyen HT (2018) The role of active silica and alumina in geopolymerization. Vietnam J Sci Technol Eng 60(2):16-23

19. Arnoult M, Perronnet M, Autef A, Rossignol S (2018) How to control the geopolymer setting time with the alkaline silicate solution. J Non-Cryst Solids 495:59-66

20. Gartner E, Maruyama I, Chen J (2017) A new model for the $\mathrm{CSH}$ phase formed during the hydration of Portland cements. Cem Concr Res 97:95-106

21. Koohestani B, Darban AK, Mokhtari P, Darezereshki E, Yilmaz E (2020) Geopolymerization of soil by sodium silicate as an approach to control wind erosion. Int J Environ Sci Technol. https://doi.org/10.1007/s13762-020-02943-2

22. Hajimohammadi A, Provis JL, van Deventer JS (2011) The effect of silica availability on the mechanism of geopolymerisation. Cem Concr Res 41(3):210-216

23. Dimas D, Giannopoulou I, Panias D (2009) Polymerization in sodium silicate solutions: a fundamental process in geopolymerization technology. J Mater Sci 44(14):3719-3730

24. Falayi T, Okonta FN, Ntuli F (2017) Desilication of fly ash and development of lightweight construction blocks from alkaline activated desilicated fly ash. Int J Environ Waste Manage 20(3):233-253

25. Provis JL (2018) Alkali-activated materials. Cem Concr Res 114:40-48

26. Jamieson EJ, Penna B, Van Riessen A, Nikraz H (2017) The development of Bayer derived geopolymers as artificial aggregates. Hydrometallurgy 170:74-81

27. Georgiou D, Papangelakis VG (1998) Sulphuric acid pressure leaching of a limonitic laterite: chemistry and kinetics. Hydrometallurgy 49(1-2):23-46

28. Solouki A, Viscomi G, Lamperti R, Tataranni P (2020) Quarry waste as precursors in geopolymers for civil engineering applications: a decade in review. Minerals 13:1-29

29. ASTM C109/C109M-12 (2012) Standard test method for compressive strength of hydraulic cement mortars (Using 2-in [50 $\mathrm{mm}$ ] cube specimen. Annual book of ASTM standards, West Conshohocken

30. Salissou Y, Panneton R (2007) Pressure/mass method to measure open porosity of porous solids. J Appl Phys 101(12):124913
31. ASTM C373-14 (2014) Standard test method for water absorption, bulk density, apparent porosity, and apparent specific gravity of fired whiteware products, ceramic tiles, and glass tiles. ASTM International, West Conshohocken, PA

32. Mashifana T, Ntuli F, Okonta F (2019) Leaching kinetics on the removal of phosphorus from waste phosphogypsum by application of shrinking core model. S Afr J Chem Eng 27:1-6

33. Siddique R, Kaur G, Rajor A (2010) WFS and its leachate characteristics. Resour Conserv Recycl 54(12):1027-1036

34. Basar HM, Aksoy ND (2012) The effect of WFS (WFS) as partial replacement of sand on the mechanical, leaching and microstructural characteristics of ready-mixed concrete. Constr Build Mater 35:508-515

35. Johnson CK (1981) Phenols in foundry waste sand modern casting. American Foundrymen's Society

36. Iloh P, Fanourakis G, Ogra A (2019) Evaluation of physical and chemical properties of South African waste foundry sand (WFS) for concrete use. Sustainability 11(1):193

37. Xu Y, Chen C, Lan Y, Wang L, Li J (2020) Desilication and recycling of alkali-silicate solution seeded with red mud for lowgrade bauxite utilization. J Mater Res Technol 9(4):7418-7426

38. Alonso-Santurde R, Andrés A, Viguri JR, Raimondo M, Guarini G, Zanelli C, Dondi M (2011) Technological behaviour and recycling potential of spent foundry sands in clay bricks. J Environ Manage 92(3):994-1002

39. Zhu G, Tan W, Sun J, Gong Y, Zhang S, Zhang Z, Liu L (2013) Effects and mechanism research of the desilication pretreatment for high-aluminum fly ash. Energy Fuels 27(11):6948-6954

40. Abdul Rahim RH, Rahmiati T, Azizli KA, Man Z, Nuruddin MF, Ismail L (2015) Comparison of using $\mathrm{NaOH}$ and $\mathrm{KOH}$ activated fly ash-based geopolymer on the mechanical properties. In: Liyana J, Muhammad FMT (eds) Materials science forum, vol 803. Trans Tech Publications Ltd., Stafa-Zurich, pp 179-184

41. Xu H, Van Deventer JSJ (2000) The geopolymerisation of alumino-silicate minerals. Int J Miner Process 59(3):247-266

42. Huseien GF, Mirza J, Ismail M, Hussin MW (2016) Influence of different curing temperatures and alkali activators on properties of GBFS geopolymer mortars containing fly ash and palm-oil fuel ash. Constr Build Mater 125:1229-1240

43. Bhardwaj B, Kumar P (2019) Comparative study of geopolymer and alkali activated slag concrete comprising waste foundry sand. Constr Build Mater 209:555-565

44. Samantasinghar S, Singh SP (2018) Effect of synthesis parameters on compressive strength of fly ash-slag blended geopolymer. Constr Build Mater 170:225-234

45. Davidovits J (1994) Properties of geopolymer cements. In: First international conference on alkaline cements and concretes, vol 1. Kiev State Technical University, Scientific Research Institute on Binders and Materials, Kiev, pp 131-149

46. Davidovits J (2002) Years of successes and failures in geopolymer applications. Market trends and potential breakthroughs. In: Geopolymer 2002 Conference, vol 28. Geopolymer Institute, Saint-Quentin, p 29

47. Leong HY, Ong DEL, Sanjayan JG, Nazari A (2016) The effect of different $\mathrm{Na}_{2} \mathrm{O}$ and $\mathrm{K}_{2} \mathrm{O}$ ratios of alkali activator on compressive strength of fly ash based-geopolymer. Constr Build Mater 106:500-511

48. Singh G, Siddique R (2012) Effect of WFS (WFS) as partial replacement of sand on the strength, ultrasonic pulse velocity and permeability of concrete. Constr Build Mater 26(1):416-422

49. Kim H, Ji-Young L (2017) Effect of ash particle sizes on the compressive strength and thermal conductivity of geopolymer synthesized with alkali activated low-calcium ground coal bottom ash. In: World of Coal Ash, Conferences Proceedings 
50. Ahmari S, Zhang L (2013) Durability and leaching behavior of mine tailings-based geopolymer bricks. Constr Build Mater 44:743-750

51. Aleem MA, Kavikumaran K, Prabunathan P, Hariharan A, Alagar M (2020) Synthesis and characterisation of sodium silicate from spent foundry sand: Effective route for waste utilisation. J Clean Prod 264:121689

52. Boussaa SA, Kheloufi A, Zaourar NB, Bouachma S (2017) Iron and aluminium removal from Algerian silica sand by acid leaching. Acta Phys Pol A 132(3):1082-1086

53. Thaarrini J, Ramasamy V (2016) Properties of foundry sand, ground granulated blast furnace slag and bottom ash based geopolymers under ambient conditions. Period Polytech Civ Eng 60(2):159-168

54. Venkatesan M, Zaib Q, Shah IH, Park HS (2019) Optimum utilization of waste foundry sand and fly ash for geopolymer concrete synthesis using D-optimal mixture design of experiments. Resour Conserv Recycl 148:114-123

55. Timakul P, Thanaphatwetphisit K, Aungkavattana P (2015) Effect of silica to alumina ratio on the compressive strength of class $C$ fly ash-based geopolymers. In: Peerapong P (ed) Key engineering materials, vol 659. Trans Tech Publications Ltd., Stafa-Zurich, pp $80-84$

56. Mashifana T, Okonta FN, Ntuli F (2018) Geotechnical properties and application of lime modified phosphogypsum waste. Mater Sci 24(3):312-318
57. South African National Standards, SANS 1215 (2008) Concrete masonry units. Standards South Africa, Pretoria

58. US Environmental Protection Agency (2015) Examining the environmental effect of spent foundry sand. https://www.found rymag.com/moldscores/epa-endorses-reuse-spent-foundry-sand. Accessed 11 July 2020

59. Dungan RS, Dees NH (2009) The characterization of total and leachable metals in foundry molding sands. J Environ Manage 90(1):539-548

60. U.S. Environmental Protection Agency (2014) Risk assessment of spent foundry sands in soil-related applications -evaluating silica-based spent foundry sand from iron, steel and aluminium foundries; U.S. EPA Office of Resource Conservation and Recovery Economics and Risk Assessment Staff; U.S. Department of Agriculture-Agriculture Research Service; The Ohio State University and RTI International: Washington, DC, USA

61. Deng A (2009) Contaminants in waste foundry sand and its leachate. Int J Environ Pollut 38(4):425-443

Publisher's Note Springer Nature remains neutral with regard to jurisdictional claims in published maps and institutional affiliations. 